\title{
Intracerebroventricular administration of adiponectin attenuates streptozotocin-induced memory impairment in rats
}

\author{
R Mazrooie $^{1}$, K Rohampour ${ }^{1}$, M Zamani ${ }^{1}$, N Hosseinmardi ${ }^{2}$, M Zeraati ${ }^{3}$ \\ ${ }^{1}$ Cellular and Molecular Research Center, Qom University of Medical Sciences, Qom, Iran \\ ${ }^{2}$ Department of Physiology, Faculty of Medicine, Shahid Beheshti University of Medical Sciences, Tehran, Iran \\ ${ }^{3}$ Department of Physiology and Pharmacology, Faculty of Medicine, Alborz University of Medical Sciences, \\ Karaj, Iran
}

Received: May 12, 2016

Accepted: February 4, 2017

\begin{abstract}
Alzheimer's disease (AD) has been reported to be linked with diabetes mellitus and insulin resistance. Adiponectin $(\mathrm{ADN})$, an adipocytokine secreted from adipose tissue, is involved in the regulation of insulin sensitivity, energy homeostasis, and mitochondrial dysfunction. In this study, we examined the effect of ADN on passive avoidance memory in animal model of sporadic $\mathrm{AD}(\mathrm{sAD})$. On days 1 and 3 after cannulation, rats received intracerebroventricular (icv) injection of streptozotocin (STZ) $(3 \mathrm{mg} / \mathrm{kg}$ ). Thirty minutes before the learning process, animals received saline or ADN in different doses $(6,60$, and $600 \mu \mathrm{g})$. The step-through latency (STL) and total time spent in the dark compartment (TDC) were recorded and analyzed. In STZ-treated rats, STL was significantly decreased, whereas TDC showed a dramatic increase. In ADN-treated rats, STL was significantly increased $(P<0.01)$ in all treatment doses. The number of entries was decreased in all applied doses; however, TDC was reduced only by the application of $6 \mathrm{ng}$ of $\mathrm{ADN}(P<0.05)$. It can be concluded that $\mathrm{ADN}$ is useful to improve the STZ-induced memory impairment. This study showed, for the first time, that icv administration of ADN could improve the memory acquisition in animal model of sAD.
\end{abstract}

Keywords: adiponectin, alzheimer's disease, dementia, memory, streptozotocin

\section{Introduction}

Alzheimer's disease (AD) is a neurodegenerative disorder associated with memory impairment and loss of multiple cognitive skills that affects one in ten people over the age of 65 years. There are two different types of AD: (a) an early-onset familial AD, which is associated with mutations in amyloid precursor protein (APP) and presenilin genes; and (b) a more common late-onset or sporadic AD (SAD) (15). The pathological presentation of $\mathrm{AD}$ involves a selective neuronal cell death associated with two hallmark lesions: the intracellular neurofibrillary tangles (NFTs) and extracellular $A \beta$ deposits in form of senile plaques (22). Accumulation of aggregated neurotoxic $A \beta$ occurs in specific brain regions (such as hippocampus and cerebral cortex) and triggers an inflammatory response which in turn leads to neuronal cell death and gradual cognitive decline (21).

Corresponding author: Kambiz Rohampour

Cellular and Molecular Research Center, Qom University of Medical Sciences

Shahid Lavasani St., 37136-49373 Qom, Iran

Phone: +98 1333690884; Fax: +98 1333690036; E-mail: rohampour@gums.ac.ir 
The hippocampus expresses high levels of insulin receptors (IRs), and intact insulin signaling is necessary for learning, memory, and synaptic plasticity (29). AD brains have lower levels of insulin, IRs, and insulin-like growth factor, which could further implicate insulin resistance in AD pathology (4). Currently, the use of intracerebroventricular (icv) streptozotocin (STZ) injections, which suppresses IR protein level, is a well-established animal model of sAD. Indeed, insulin dysfunction leads to overactivation of glycogen synthase kinase- $3 \beta$, which in turn causes tau hyper phosphorylation and NFT formation and potentiates $\mathrm{A} \beta$ aggregation (23).

Epidemiologic studies have shown that overweight and obesity are associated with cognitive impairment, dementia, and increased risk of AD. Proteins secreted from the adipose tissue, known as adipokines, have important functions in regulating the metabolism of the whole body (14).

Adiponectin $(\mathrm{ADN})$, the most abundant adipokine present in plasma and cerebrospinal fluid, is inversely correlated with obesity and diabetes mellitus type 2 (T2DM) (10). ADN exerts its biological actions through its known receptors, adipoR-1 and adipoR-2, which are prevalently expressed in skeletal muscle and liver, respectively; however, both receptors have also been found in hypothalamus and hippocampal neurons (12). ADN diminishes the expression of pro-inflammatory cytokines and increases the anti-inflammatory ones (26). Many reports indicate that ADN has insulin-sensitizing effects and is decreased in insulinresistant patients (10). Clinical studies have shown that ADN level decreases in T2DM, mild cognitive impairment (MCI), and AD (25). Administration of ADN could attenuate insulin resistance, possibly by decreasing tissue triglyceride levels (27). Considering insulin resistance as a promoting factor in $\mathrm{AD}$, the aim of this study was to examine whether the insulinsensitizing effects of ADN could reverse the STZ-induced dementia in rats.

\section{Materials and Methods}

\section{Animals}

Adult male Wistar rats (250-300 g, Pasteur Institute, Iran) were housed four per cage in a temperature controlled room $\left(22 \pm 2{ }^{\circ} \mathrm{C}\right)$, with a $12-12 \mathrm{~h}$ light-dark cycle and ad libitum access to food and water. All studies were performed in accordance with the ethical guidelines of the "Ethical Committee of Qom University of Medical Sciences," which are based on the "NIH Guide for the Care and Use of Laboratory Animals."

\section{Experimental procedure}

A total of 40 rats were divided into six experimental groups $(n=7)$, namely, Intact, Sham, STZ, STZ+ADN $(6,60$, and $600 \mathrm{ng})$, which have been shown to be effective in other dose-response studies (3). Sham group received icv injection of $10 \mu \mathrm{l}$ of artificial cerebrospinal fluid (aCSF; containing $147 \mathrm{mM} \mathrm{NaCl}, 2.9 \mathrm{mM} \mathrm{KCl}, 1.6 \mathrm{mM} \mathrm{MgCl}, 1.7 \mathrm{mM} \mathrm{CaCl}$, and $2.2 \mathrm{mM}$ dextrose), whereas the STZ group received STZ ( $3 \mathrm{mg} / \mathrm{kg}$, icv) on days 1 and 3 after cannulation.

\section{Treatments}

Rats were anesthetized with a mixture of ketamine [80 mg/kg, intraperitoneal (ip)] and xylazine $(20 \mathrm{mg} / \mathrm{kg}$, ip) and unilaterally implanted with cannulae (23 gauge) placed in the lateral ventricles; anteroposterior: Bregma, mediolateral: $\pm 1.5 \mathrm{~mm}$ "lateral to the" midline, 
and dorsoventral: $-3 \mathrm{~mm}$ according to the atlas of Paxinos (18). Two small screws were inserted into the skull and cannulae were fixed to them using dental cement. After recovery, icv injections were performed by an injection needle (30 gauge) connected to a $10-\mu 1$ Hamilton microsyringe. Rats were conscious during injection and gently restrained by hand. The injection procedure took $2 \mathrm{~min}$, and the injection needles (extending $1 \mathrm{~mm}$ from the end of the guide cannulae) were left in place for $1 \mathrm{~min}$. On days 1 and 3 after cannulation, animals received $10 \mu \mathrm{l}$ volume of vehicle (aCSF) or STZ (3 mg/kg) dissolved in aCSF (20). The timeline of different procedures is shown in Fig. 1.

\section{Behavioral assessment}

The passive avoidance task was used to examine the memory acquisition and retrieval based on the negative reinforcement, as described elsewhere (28). Shortly, the step-through passive avoidance apparatus consisted of a light and a dark chamber $(30 \mathrm{~cm} \times 20 \mathrm{~cm} \times$ $20 \mathrm{~cm}$ each). The floor of the dark chamber is consisted of $2 \mathrm{~mm}$ thin, electrified, stainless steel rods. On days 1 and 3, rats received STZ (3 mg/kg, icv). On day 6, animals were allowed to explore each chamber for adaptation. On day 7, saline or ADN was injected $30 \mathrm{~min}$ before the learning process. Rats were then placed in the lighted chamber, and a shock $(50 \mathrm{~Hz}, 0.5 \mathrm{~mA}, 2 \mathrm{~s})$ was delivered, following entrance to the dark compartment. After $5 \mathrm{~min}$, the immediate memory was tested and step-through latency (STL) and the number of entries into the dark compartment were measured. Early and late retention tests were performed 1 and 7 days after training, and the time spent in the dark compartment (TDC) was recorded up to $300 \mathrm{~s}$.

\section{Statistical analysis}

Results are expressed as mean \pm SEM of STL, TDC, and number of entries. Data were analyzed using ordinary one-way analysis of variances (ANOVA). Where appropriate, ANOVA was followed by Bonferroni post-hoc test to determine the group differences. $P<0.05$ was considered as level of statistical significance in all comparisons.

\section{Histological verification}

Following behavioral testing, animals were deeply anesthetized by $\mathrm{CO}_{2}$ inhalation, decapitated, and the brains were removed and fixed in formalin. For histological examination of injection site, $100-\mu \mathrm{m}$-thick coronal sections were taken, and the injection sites were examined for each side under light microscopy. Among all experiments, the injection trace of four rats did not fit to the lateral ventricle, and these data were excluded from further analysis.

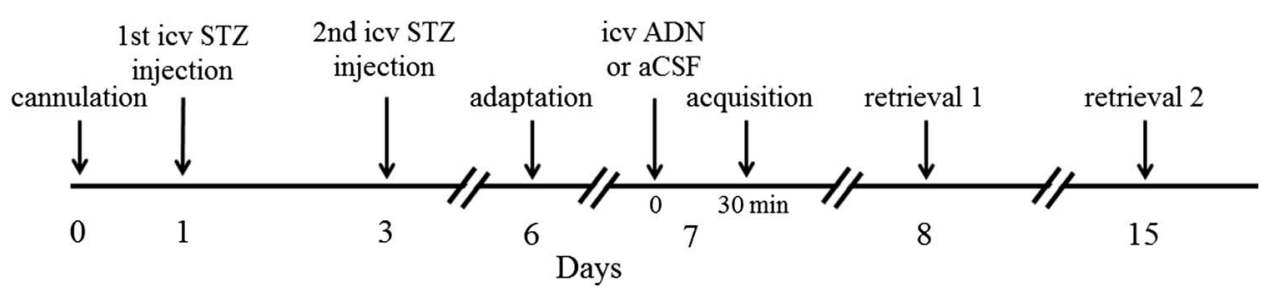

Fig. 1. Timeline of the experimental procedure. One week after cannulation, icv injection of ADN/aCSF was performed $30 \mathrm{~min}$ before training 


\section{Results}

Effect of icv injection of STZ on memory acquisition in passive avoidance task

The sham-operated rats, which received aCSF (icv) instead STZ, did not show any significant difference compared with the naive animals in any of the parameters ( $t$-test, data not shown). As shown in Fig. 2A, the mean STL of rats receiving STZ was $11.3 \pm 7.8 \mathrm{~s}$, which was significantly $(P<0.001)$ less than the STL of sham-operated rats $(265.7 \pm 34.3 \mathrm{~s})$. Comparison of the number of trials to acquisition showed a significant difference between sham and STZ-treated rats $(1.14 \pm 0.1$ vs. $2.7 \pm 0.5, P<0.01)$. The cutoff time was $300 \mathrm{~s}$ (Fig. 2B).

Acute icv ADN administration prevented the STL reduction in STZ-treated rats

Administration of different doses $(6,60$, and $600 \mathrm{ng}$ ) of ADN into the cerebral ventricles $30 \mathrm{~min}$ prior to training, improved both the acquisition and retrieval of passive avoidance

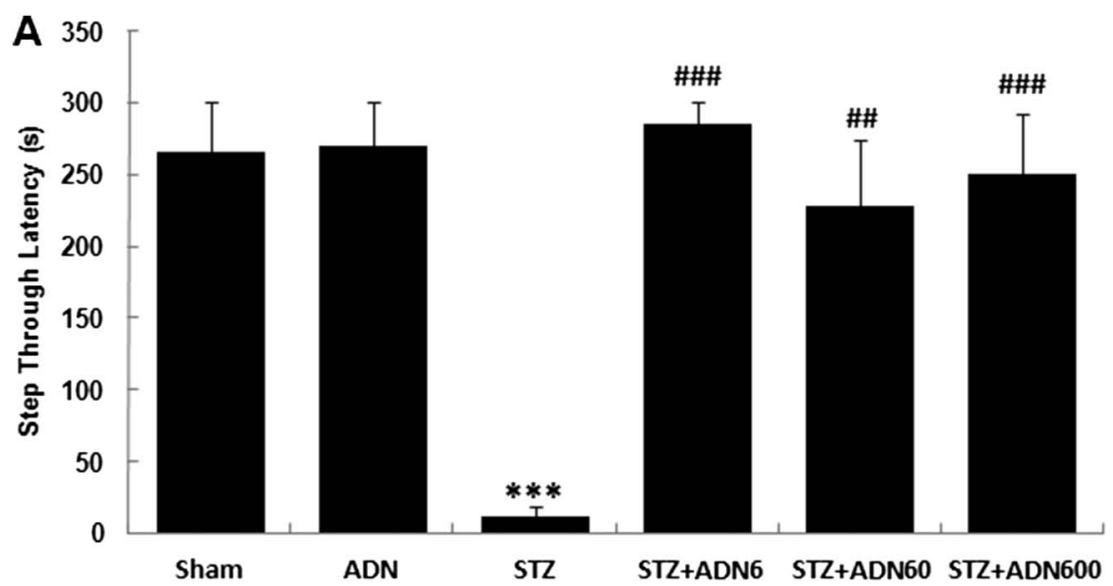

B

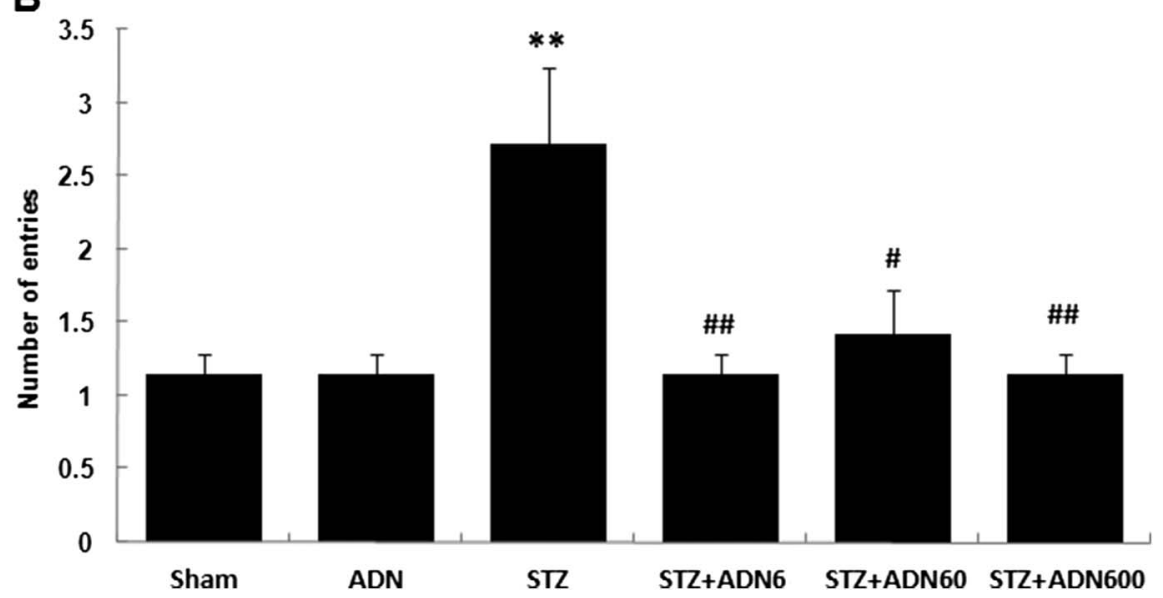

Fig. 2. Effects of icv-STZ injection and ADN treatment on STL during acquisition phase (A) and on the number of trails

to acquisition (B). Values are expressed as mean \pm SEM. ${ }^{*} P<0.05, * * * P<0.001$, STZ vs. Sham. ${ }^{\#} P<0.05$,

${ }^{\# \#} P<0.01,{ }^{\# \# \#} P<0.001, \mathrm{STZ}+\mathrm{ADN}$ vs. STZ. ( $n=7$, ANOVA multiple group comparison, Bonferroni post-hoc test) 
memory (Fig. 2A). Injection of $6 \mathrm{ng}$ of ADN significantly increased the STL (STZ: $2.7 \pm$ $0.5 \mathrm{~s}$ vs. STZ+ADN6: $285.3 \pm 14.7 \mathrm{~s}, P<0.01)$. Also, ADN at the dose of 60 and $600 \mathrm{ng}$ enhanced the STL compared with STZ-treated rats (STZ: $2.7 \pm 0.5 \mathrm{~s}$ vs. STZ+ADN60: $227.6 \pm 47.2 \mathrm{~s}, P<0.05$ and STZ: $2.7 \pm 0.5 \mathrm{~s}$ vs. STZ+ADN600: $250.4 \pm 41.8 \mathrm{~s}, P<0.01)$. The number of trials to acquisition showed the same pattern of improvement; STZ-treated rats entered $2.7 \pm 0.5$ times, while $6 \mathrm{ng}$ of $\mathrm{ADN}$ treatment decreased the number of entries to $1.14 \pm 0.1(P<0.01)$. Injection of 60 and $600 \mathrm{ng}$ of $\mathrm{ADN}$ reduced the trials to $1.4 \pm 0.3$ $(P<0.05)$ and $1.14 \pm 0.1(P<0.01)$, respectively (Fig. 2B).

ADN administration before training improved the early memory retrieval

As shown in Fig. 3A, one day after training STZ-treated animals spent significantly longer time in the dark compartment compared with the sham group (STZ: $204.1 \pm 35.5$ s vs. $29.3 \pm 29.3 \mathrm{~s}$,
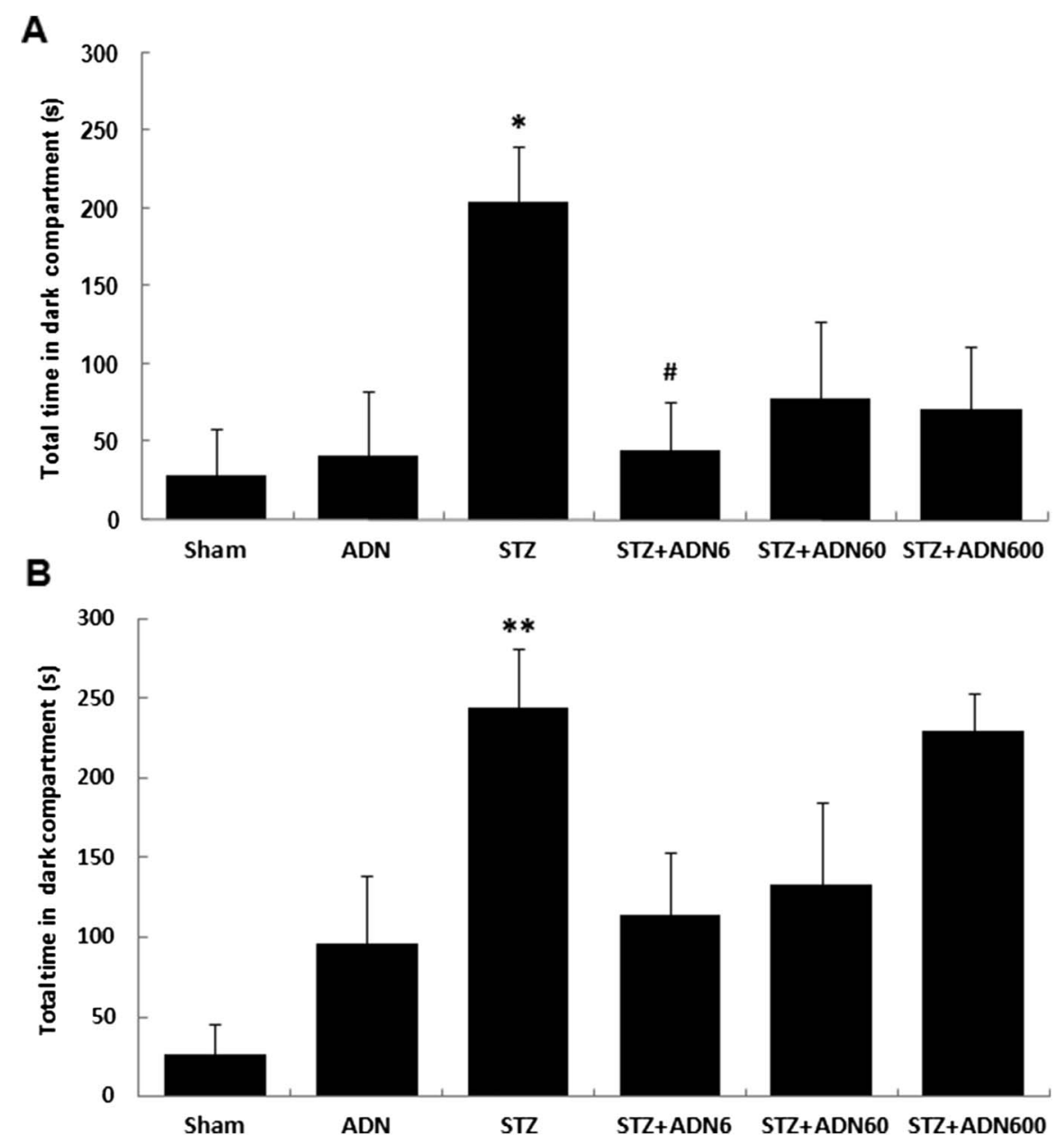

Fig. 3. Early and late retrieval in passive avoidance task shown as TDC on day 1 (A) and day 7 after acquisition (B). TDC is indicated in seconds, as mean \pm SEM. ${ }^{*} P<0.05, * * P<0.01$, STZ vs. Sham. ${ }^{*} P<0.05$, STZ vs. STZ+ADN. $(n=7$, ANOVA, Bonferroni post-hoc test) 
$P<0.05$ ). The same trend in memory impairment was observed 7 days after training (Sham: $27.1 \pm 18.3$ vs. STZ: $244.7 \pm 37.5, P<0.01$ ), which is shown in Fig. 3 B.

One-way ANOVA with Bonferroni post-hoc test revealed that ADN only at the dose of $6 \mathrm{ng}$ could improve early memory retrieval, one day after training (STZ: $204.1 \pm 35.5 \mathrm{~s}$ vs. $50.4 \pm 26 \mathrm{~s}, P<0.05)$. Other doses could not exert a significant effect on early and late memory retrieval (Fig. 3A and B). The injection of ADN in intact animals did not cause any significant change in assessed parameters compared with the sham-operated rats.

\section{Discussion}

The results of this study indicate that icv administration of ADN before the acquisition process of learning could improve the memory retrieval in rat model of dementia.

Reduced cellular response to insulin leads to hyperinsulinemia, and excessive insulin increases cell proliferation and also induces oxidative stress (16). Insulin can improve memory, and insulin deficiency plays a key role in memory impairment and development of dementia (6). In contrast to adipokines, such as tumor necrosis factor- $\alpha$ (TNF $\alpha$ ) and monocyte chemoattractant protein-1, which cause insulin resistance, ADN expression is reduced in insulin-resistant rats (11). Pro-inflammatory cytokines are also involved in insulin resistance. Elevated levels of interleukin-1 $\beta$ (IL-1 $\beta$ ), IL-10, and TNF $\alpha$, which are inversely related to serum ADN, increase the risk of T2DM (13). Several pieces of evidence suggest that the insulin-sensitizing action of ADN depends on modulation of insulin-signaling molecules and regulation of glucose and lipid metabolism (2). ADN stimulates lipolysis and lipid oxidation, and thereby regulates lipid transfer into non-adipose tissues. Ceramide, a cytotoxic and insulin-desensitizing lipid metabolite, is converted to sphingosine-1-phosphate, a process triggered by ADN that improves hepatic insulin action (24).

Some adipokines such as leptin and ADN are involved in the development of dementia. Clinical studies have shown that circulating ADN decreases in MCI and AD (25). This is consistent with our findings that exogenous ADN injection could improve the impaired memory after insulin signaling deficiency. Others have reported that chronic donepezil treatment decreases serum leptin, whereas it increases ADN levels in patients with AD (17). García-Casares et al. (7) showed that lower levels of ADN correlated with a lower gray matter volume and reduced cerebral glucose metabolism in temporal regions. The brain of older patients is more vulnerable to lower glucose levels. It is known that astrocytes transform glucose into lactate, which contributes to synapse and memory formation (8).

A vast number of leptin and ADN receptors are expressed within the hippocampus, which is involved in learning and memory. ADN has been shown to reduce the level of oxidative stress and kainic acid-induced cytotoxicity in cultured hippocampal neurons. These antioxidative and neuroprotective effects of ADN are mediated by the $\alpha$-amino-3-hydroxy-5methyl-4-isoxazolepropionic acid pathway (19). On the other hand, it has been shown that some adipokines, such as leptin, enhance N-methyl-D-aspartate receptor function and induce hippocampal long-term potentiation (9). Some evidence from our laboratory showed that icv administration of ADN could also potentiate synaptic efficacy (unpublished data), which can further emphasize the involvement of ADN in learning and memory.

ADN directly strengthens hepatic insulin signaling by upregulating IRS-2 expression through an interleukin (IL)-6-dependent pathway (1). The adaptor protein APPL1 has been identified as a key scaffold protein to mediate some actions of both insulin and ADN 
receptors. Thus, APPL1 has been implicated in the insulin-sensitizing effect of ADN (5). This signaling cross-talk between $\mathrm{ADN}$ and insulin receptor could, in part, explain the memory improving effect of ADN observed in this study.

\section{Conclusion}

The results of this study showed, for the first time, a direct link between ADN, as an insulin-sensitizing adipokine, and memory improvement in an animal model of sAD. Further studies are needed to elucidate the molecular mechanisms underlying the close relationship between ADN, memory, and dementia.

\section{Acknowledgements}

This study was supported by a grant from Qom University of Medical Sciences in Qom, Iran. The authors alone are responsible for the content and writing of the paper.

\section{Conflict of interest}

There is no conflict of interest for any of the contributing authors.

\section{REFERENCES}

1. Awazawa M, Ueki K, Inabe K, Yamauchi T, Kubota N, Kaneko K, Kobayashi M, Iwane A, Sasako T, Okazaki Y, Ohsugi M, Takamoto I, Yamashita S, Asahara H, Akira S, Kasuga M, Kadowaki T: Adiponectin enhances insulin sensitivity by increasing hepatic IRS-2 expression via a macrophage-derived IL-6-dependent pathway. Cell Metab. 13, 401-412 (2011)

2. Benomar Y, Amine H, Crépin D, Al Rifai S, Riffault L, Gertler A, Taouis M: Central Resistin/TLR4 impairs adiponectin signaling contributing to insulin and FGF21 resistance. Diabetes 65, 913-926 (2016)

3. Coope A, Milanski M, Araújo EP, Tambascia M, Saad MJ, Geloneze B, Velloso LA: AdipoR1 mediates the anorexigenic and insulin/leptin-like actions of adiponectin in the hypothalamus. FEBS Lett. 582, 1471-1476 (2008)

4. Craft S: Alzheimer disease: insulin resistance and AD - extending the translational path. Nat. Rev. Neurol. 8, 360-362 (2012)

5. Deepa SS, Dong LQ: APPL1: role in adiponectin signaling and beyond. Am. J. Physiol. Endocrinol. Metab. 296, E22-E36 (2009)

6. De Felice FG, Benedict C: A key role of insulin receptors in memory. Diabetes 64, 3653-3655 (2015)

7. García-Casares N, García-Arnés JA, Rioja J, Ariza MJ, Gutiérrez A, Alfaro F, Nabrozidis A, González-Alegre P, González-Santos P: Alzheimer's like brain changes correlate with low adiponectin plasma levels in type 2 diabetic patients. J. Diabetes Complications 30, 281-286 (2016)

8. González-Reyes RE, Aliev G, Ávila-Rodrigues M, Barreto GE: Alterations in glucose metabolism on cognition: a possible link between diabetes and dementia. Curr. Pharm. Des. 22, 812-818 (2016)

9. Harvey J, Solovyova N, Irving A: Leptin and its role in hippocampal synaptic plasticity. Prog. Lipid Res. 45, 369-378 (2006)

10. Hotta K, Funahashi T, Arita Y, Takahashi M, Matsuda M, Okamoto Y, Iwahashi H, Kuriyama H, Ouchi N, Maeda K, Nishida M, Kihara S, Sakai N, Nakajima T, Hasegawa K, Muraguchi M, Ohmoto Y, Nakamura T, Yamashita S, Hanafusa T, Matsuzawa Y: Plasma concentrations of a novel, adipose-specific protein, adiponectin, in type 2 diabetic patients. Arterioscler. Thromb. Vasc. Biol. 20, 1595-1599 (2000)

11. Hu E, Liang P, Spiegelman BM: AdipoQ is a novel adipose-specific gene dysregulated in obesity. J. Biol. Chem. 271, 10697-10703 (1996)

12. Jeon BT, Shin HJ, Kim JB, Kim YK, Lee DH, Kim KH, Kim HJ, Kang SS, Cho GJ, Choi WS, Roh GS: Adiponectin protects hippocampal neurons against kainic acid-induced excitotoxicity. Brain Res. Rev. 61, 81-88 (2009) 
13. Liu C, Feng X, Li Q, Wang Y, Li Q, Hua M: Adiponectin, TNF- $\alpha$ and inflammatory cytokines and risk of type 2 diabetes: a systematic review and meta-analysis. Cytokine 86, 100-109 (2016)

14. Matsuzawa Y: Adipocytokines and metabolic syndrome. Semin. Vasc. Med. 5, 34-39 (2005)

15. Merlo S, Spampinato S, Canonico PL, Copani A, Sortino MA: Alzheimer's disease: brain expression of a metabolic disorder? Trends Endocrinol. Metab. 21, 537-544 (2010)

16. Midaoui AE, Talbot S, Lahjouji K, Dias JP, Fantus IG, Couture R: Effects of alpha-lipoic acid on oxidative stress and kinin receptor expression in obese zucker diabetic fatty rats. J. Diabetes Metab. 6, 1-7 (2015)

17. Pákáski M, Fehér A, Juhász A, Drótos G, Fazekas OC, Kovács J, Janka Z, Kálmán J: Serum adipokine levels modified by donepezil treatment in Alzheimer's disease. J. Alzheimers Dis. 38, 371-377 (2014)

18. Paxinos G, Watson C (1986): The Rat Brain in Stereotaxic Coordinates. Academic Press, New York

19. Qiu G, Wan R, Hu J, Mattson MP, Spangler E, Liu S, Yau SY, Lee TM, Gleichmann M, Ingram DK, So KF, Zou S: Adiponectin protects rat hippocampal neurons against excitotoxicity. Age (Dordr.) 33, 155-165 (2011)

20. Samy DM, Ismail CA, Nassra RA, Zeitoun TM, Nomair AM: Downstream modulation of extrinsic apoptotic pathway in streptozotocin-induced Alzheimer's dementia in rats: erythropoietin versus curcumin. Eur. J. Pharmacol. 770, 52-60 (2016)

21. Selkoe DJ: Alzheimer's disease results from the cerebral accumulation and cytotoxicity of amyloid beta-protein. J. Alzheimers Dis. 3, 75-80 (2001)

22. Smith MA: Alzheimer disease. Int. Rev. Neurobiol. 42, 1-54 (1998)

23. Solano DC, Sironi M, Bonfini C, Solerte SB, Govoni S, Racchi M: Insulin regulates soluble amyloid precursor protein release via phosphatidyl inositol 3 kinase-dependent pathway. FASEB J. 14, 1015-1022 (2000)

24. Tao C, Sifuentes A, Holland WL: Regulation of glucose and lipid homeostasis by adiponectin: effects on hepatocytes, pancreatic $\beta$ cells and adipocytes. Best Pract. Res. Clin. Endocrinol. Metab. 28, 43-58 (2014)

25. Teixeira AL, Diniz BS, Campos AC, Miranda AS, Rocha NP, Talib LL, Gattaz WF, Forlenza OV: Decreased levels of circulating adiponectin in mild cognitive impairment and Alzheimer's disease. Neuromolecular Med. 15, 115-121 (2013)

26. Wolf AM, Wolf D, Rumpold H, Enrich B, Tilg H: Adiponectin induces the anti-inflammatory cytokines IL-10 and IL-1RA in human leukocytes. Biochem. Biophys. Res. Commun. 323, 630-635 (2004)

27. Yamauchi T, Kamon J, Waki H, Terauchi Y, Kubota N, Hara K, Mori Y, Ide T, Murakami K, Tsuboyama-Kasaoka N, Ezaki O, Akanuma Y, Gavrilova O, Vinson C, Reitman ML, Kagechika H, Shudo K, Yoda M, Nakano Y, Tobe K, Nagai R, Kimura S, Tomita M, Froguel P, Kadowaki T: The fat-derived hormone adiponectin reverses insulin resistance associated with both lipoatrophy and obesity. Nat. Med. 7, 941-946 (2001)

28. Zamani M, Rohampour K, Zeraati M, Hosseinmardi N, Kazemian MM: Pre-training catechin gavage prevents memory impairment induced by intracerebroventricular streptozotocin in rats. Neurosciences (Riyadh) 20, 225-229 (2015)

29. Zhao WQ, Alkon DL: Role of insulin and insulin receptor in learning and memory. Mol. Cell. Endocrinol. 177, 125-134 (2001) 